\title{
ALGUNOS COMENTARIOS CRÍTICOS A LAS CRÍTICAS DE JUAN CARLOS BAYÓN Y FRANCISCO LAPORTA
}

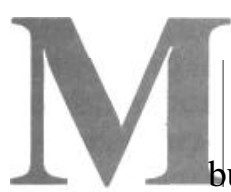
i trabajo sobre la justificación ética de los deberes positivos generales ha sugerido una serie de agudas críticas a dos distinguidos filósofos del derecho, Juan Carlos Bayón y Francisco Laporta. Se trata aquí de dos excelentes contride promover aún más la discusión, he de limitarme a la consideración, en cada caso, de dos objeciones que me parecen centrales.

Juan Carlos Bayón pone en duda

a) mi distinción entre «daño» $\mathrm{y}$ «beneficio»y

b) el contenido mismo del deber positivo general.

Por su parte, Francisco Laporta critica

c) la vinculación causal que pueda existir entre el no cumplimiento del deber positivo general de prestar ayuda y situaciones tan graves como la del hambre en el mundo; $y$

d) la existencia misma de los deberes positivos generales ya que éstos en realidad se diluyen en deberes positivos especiales.

\section{I}

a) El argumento básico de Bayón en contra de mi distinción entre «daño» $\mathrm{y}$ «beneficio» es que en mi trabajo no habría «diferenciado adecuadamente los sentidos descriptivo y normativo» de ambos conceptos. El acento, según Bayón, debería recaer sobre el aspecto normativo: «no se tiene el deber de actuar porque la abstención provoque un daño, sino que la abstención provoca un daño si se tenía el deber de actuar» (subrayado en el original). Dicho con otras palabras y utilizando una terminología bien conocida por los juristas, no se trataría aquí de un caso de 'mala in se' sino de 'mala prohibita'.

Esta distinción, que podría tener algún sentido en el plano jurídico, conduce a situaciones realmente inaceptables en el campo de la ética. En efecto, aceptar la sugerencia de Bayón significa que los hombres se dañan recíprocamente sólo si violan un mandato normativo. Un ejemplo puede aclarar esta tesis. Supongamos que en una sociedad S* está ordenado privar de su propiedad y hasta de la vida a las personas de pelo blanco. Quienes cumplen con este mandato, es decir, saquean y matan a los canosos no los dañan (puesto que cumplen con la norma) y en cambio, quienes se abstienen de hacerlo los dañan. Y para los canosos la situación sería la siguiente: sólo podrían decir que han sido dañados si no los saquean o matan y en caso de que tal trágico evento sucediera no podrían alegar que han sido dañados. 
No dudo que ésta no es la conclusión a la que desea llegar Juan Carlos Bayón, pero ella se infiere si se acepta que sólo se daña con una abstención «si se tenía el deber de actuar».

La referencia a Joel Feinberg e indirectamente a la máxima «volenti non fit injuria», en donde «injuria», como el propio Bayón señala correctamente, puede ser entendido como «daño» o como «agravio», me parece que no aclara la situación. Como es sabido, la formula «volenti» tiene una larga tradición que se remonta no sólo al derecho romano sino también a Aristóteles, quien distinguía entre «agravio» y «daño» (en la terminología de Feinberg, entre «wrong» $\mathrm{y}$ «harm»). El primero tenía un sentido jurídico del que carecía el segundo. Por ello podía decirse que quien carece de derechos no pude ser «agraviado». Pero de aquí no se infiere que no pueda ser «dañado» (cfr. Aristóteles, 1985, 260, 265). En el caso del ejemplo, los canosos no habrían sido «agraviados» pero sí «dañados». Y esto último es lo que aquí nos interesa.

Pero el propio Bayón no parece aceptar al final de su trabajo el prius conceptual de «deber» con respecto a «daño», que postula en la primera parte de su artículo. En efecto, cuando trata la cuestión de la fundamentación de los deberes positivos generales, toma como punto de partida el concepto de autonomía, entendida como capacidad de optar entre diferentes planes de vida. Los deberes positivos generales contribuirían (y pienso que tiene toda la razón) a la defensa o promoción de esta autonomía. Pero las lesiones de la autonomía (sea por acción o por omisión) «dañan» no porque estén prohibidas sino que justamente se las prohibe porque se considera que la autonomía de la persona es un bien valioso.

O sea, que o bien Bayón tiene que renunciar a su versión de «daño» como concepto normativo o bien tiene que abandonar su justificación de los deberes positivos recurriendo al concepto de autonomía. Creo que lo correcto es lo primero, sólo que en este caso la objeción queda sin efecto.

b) Por lo que respecta a la determinación del contenido de los deberes positivos generales, admito que el concepto de sacrificio «trivial»o «mínimo» es vago y puede dar lugar a perplejidades en los casos concretos. Pero no me parece que esta vaguedad quede superada si se sustituye «trivial» por «gravoso» o si se añade el comparativo «más que» trivial o mínimo. Cuando se trata de la delimitación exacta del contenido de la obligación conviene quizás recordar las palabras de C.D. Broad: «no es una objeción decir que es totalmente imposible determinar exactamente dónde está este límite en cada caso particular. Es verdad que esto sucede, pero es una dificultad demasiado común en la ética como para que tenga que preocuparnos y sabemos que nos sentimos satisfechos cuando en las cuestiones éticas podemos fijar límites superiores e inferiores que no resultan demasiado ridículos» (1916, 389-390).

\section{II}

c) Tiene razón Francisco Laporta cuando señala la diferencia que existe entre situaciones en las que los actores están perfectamente individualizados 
y aquellas que «presentan perfiles cuantitativos destacados». Y es verdad también que no pocos autores tienen la tendencia a equiparar sin más los casos en los que están en juego las acciones o las omisiones de dos o tres personas con aquellos en los que intervienen millones de seres. Espero no haber cometido este pecado.

Pero de aquí no puede inferirse que el cumplimiento de deberes positivos sea inútil cuando se trate de situaciones complejas por el número de personas que en ellas intervienen, tal como parece sugerirlo Laporta. En efecto, según él «...si la complejidad de las condiciones y la dificultad de su presencia son tales que puede afirmarse que el estado de cosas en cuestión tiene una probabilidad cercana a la nada de alterarse en uno $u$ otro sentido como consecuencia de mi acción o de mi opinión, entonces es problemático pensar que éstas puedan ser causa de la presencia o ausencia de ese estado de cosas». Desde luego, si es verdad que no puedo modificar en nada un estado de cosas dado es también verdad que no cabe imputar su existencia o desaparición a mi comportamiento. Esto es analíticamente verdadero. Pero evidentemente Laporta no desea formular un juicio analítico sino empírico, es decir, referido a la relación causal entre mi comportamiento y un determinado estado de cosas en cuya conformación intervienen acciones y omisiones de un gran número de personas. En este caso, según Laporta, como el volumen de causas posibles es enorme, no se puede predecir cuál acción u omisión ha provocado tal o cuál efecto. De acuerdo; más aún, podría hablarse aquí de condiciones necesarias y suficientes complejas que incluyen en muchos casos (por ejemplo, en el del hambre en el mundo) no sólo la falta de ayuda externa sino también la existencia de regímenes políticos injustos o fenómenos tan heterogéneos como las pautas de comportamiento familiar frente al control de la natalidad, la cultura política del pueblo o hasta las condiciones naturales. Todo esto es verdad, pero pienso que también lo es que la eliminación o reducción de la complejidad de este conjunto de condiciones es la vía más adecuada para su superación definitiva. En este sentido la ayuda no es inútil aunque sí puede no ser suficiente. Hay pruebas empíricas de la eficacia de la ayuda prestada sobre la base de contribuciones individuales para paliar situaciones de extrema pobreza o de hambre que no permiten calificar de inútiles a este tipo de empresas, por más que para asegurar su eficacia haya sido necesaria la intervención de otros factores (por ejemplo, distribución adecuada de los alimentos donados). Cuál sea la participación individual en la obtención del monto de la ayuda determinará también la relación causal de la acción u omisión individual con respecto al resultado obtenido. Pero, en todo caso, si la ayuda es útil y ésta es obtenida a través de aportes individuales, pienso que puede inferirse que no es irrelevante cumplir con la obligación general positiva de prestar ayuda.

Desde el punto de vista de la responsabilidad moral, creo que el argumento de Laporta es similar al de quien sostiene que, dado que su acción u omisión no altera en medida apreciable (en el más estricto sentido de la palabra) la conservación, promoción o destrucción de un bien común (el sistema democrático, un medio ambiente no contaminado), no habría por qué adscribir «una gran responsabilidad moral» a quien no participa en las elecciones o arroja basura a un río ya que siempre podría aducir que su omisión o su acción no altera mayormente ni el resultado de las elecciones ni el gra- 
do de contaminación ambiental. Este es un hecho cierto como lo es también que «del hecho de que para todos los miembros de un grupo sea ventajoso el que se alcance el objetivo perseguido por el grupo no se infiere que hayan de orientar su comportamiento hacia la obtención del objetivo del grupo, aun cuando actúen de manera plenamente racional y siguiendo sus propios intereses» (Olson, 1968, 2, subrayado en el original). Quien se abstiene de tirar basura al río o participa en las elecciones no está pues guiado por su propio interés egoísta o de conveniencia. inmediato sino que la motivación de su conducta ha de buscarse en otras razones que no son prudenciales sino justamente morales. Por eso es que resulta insuficiente la explicación del comportamiento electoral de las personas recurriendo a la manida frase según la cual «cada voto cuenta». Quien participa en una elección o no arroja basura al río lo hace distanciándose de sus propios intereses y siguiendo su propia convicción moral de lo que es correcto. Asume en este sentido su «responsabilidad moral» y por ello es posible formular un reproche moral a quien no actúa de esta forma, sin que importe la relevancia fáctica de su acto (cfr. Kliemt, 1986).

d) En mi trabajo he sostenido que en muchos casos el cumplimiento de deberes positivos requiere coordinación de esfuerzos y no reducido grado de especialización. Francisco Laporta generaliza esta afirmación e infiere que ello significa que todos los deberes positivos se diluyen en última instancia en deberes positivos especiales. Creo que esto no es correcto. Cuando el deber positivo general consiste, por ejemplo, en donar una parte proporcional de los ingresos (sea que se trate de un sacrificio «trivial», «gravoso» o determinado por el principio de diferencia) para aliviar la situación de quienes se encuentran en situación de penuria, no cabe hablar de roles sociales o de «deberes posicionales». Para la imposición de estos deberes desde el punto de vista ético no es necesario la existencia del Estado. Pero el Estado sí es relevante tanto en uno como en otro caso para asegurar su cumplimiento y también sancionar su incumplimiento. (Basta pensar en el deber positivo de pagar impuestos con miras a asegurar la realización del bien común).

Comparto con Francisco Laporta su preocupación por una «moralidad pensada para las instituciones» y los problemas éticos vinculados con la «reprivatización de ciertas demandas básicas de ética social y política». A ellos me he referido en la última parte de mi trabajo.

\section{BIBLIOGRAFÍA}

Aristóteles (1985): Ética Nicomáquea, Madrid.

Broad, C.D. (1916): «On the Function of False Hypotheses in Ethics» en International Journal of Ethics, 26, págs. 377-97.

Kliemt, Hartmut (1986): Die These von der Trennung von Politik und Moral, manuscrito inédito.

Olson, Mancur, Jr. (1968): Die Logik des kollektiven Hendelns, Tubinga.

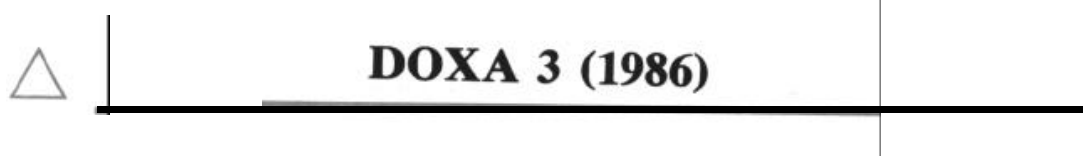

